\title{
Quartzo magmático e hidrotermal do depósito de ouro São Jorge, Província Aurífera do Tapajós, Pará: petrografia, microscopia eletrônica de varredura-catodoluminescência e implicações metalogenéticas
}

\author{
Magmatic and hydrothermal quartz of the São Jorge gold deposit, \\ Tapajós Gold Province, Pará: Petrography, scanning electron \\ microscopy-cathodoluminescence and metallogenetic implications
}

\author{
Aldemir de Melo Sotero ${ }^{1,2 *}$, Claudio Nery Lamarão ${ }^{1,2}$, \\ Gisele Tavares Marques ${ }^{2}$, Paulo Roberto Soares Rodrigues ${ }^{1,2}$
}

\begin{abstract}
RESUMO: Estudos em cristais de quartzo presentes nas associaçóes minerais para a área do depósito de ouro São Jorge, Província Aurífera do Tapajós, sudoeste do estado do Pará, identificaram quatro tipos morfológico-texturais (Qz1, Qz2, Qz3 e Qz4) com base em imagens de microscopia eletrônica de varredura-catodoluminescência. Nas rochas mais preservadas do Granito São Jorge Jovem, ricas em anfibólio e biotita (associaçōes 1 e 2), dominam cristais anédricos de quartzo magmático com luminescência alta a moderada (Qz1). Nas rochas parcialmente alteradas (associaçóes 2 e 3), fluidos pós-magmáticos a hidrotermais afetaram o granito e percolaram fraturas do Qz1 e cristalizaram Qz2 não luminescente (escuro). Nas rochas mais intensamente alteradas (associaçấo 4), sucessivos processos de alteração, dissolução e recristalizaçấo deram origem a cristais de quartzo zonados subédricos (Qz3) e euédricos (Qz4). Imagens por elétrons retroespalhados e análises semiquantitativas por espectroscopia por dispersão de energia identificaram duas geraçốes de ouro: Au1, enriquecido em $\mathrm{Ag}$ (4,3 a $23,7 \%)$ e associado a cristais de pirita; Au2, enriquecido em Te (1,1 a 17,2\%) e incluso ou associado ao Qz4. O estudo de microscopia eletrônica de varredura-catodoluminescência forneceu informaçôes importantes que foram preservadas na estrutura do quartzo. A evolução morfológico-textural desse mineral em diferentes estágios evidencia a açấo gradativa do hidrotermalismo nas rochas e nas associaçóes minerais do depósito São Jorge. A mineralizaçáo aurífera do depósito foi caracterizada quimicamente (espectroscopia por dispersão de energia) e parageneticamente (pirita, esfalerita e Qz4), podendo ser dividida em geraçóes ou eventos mineralizantes distintos. A eficiência da metodologia utilizada neste estudo foi comprovada, permitindo sua aplicação em estudos de outros depósitos hidrotermais.
\end{abstract}

PALAVRAS-CHAVE: Tapajós; MEV; Catodoluminescência; Quartzo; Ouro.

\begin{abstract}
Studies in crystals of quartz present in the mineral associations to the area of the São Jorge gold deposit, Tapajós Gold Province, southwest of the Pará state, identified four morphological and textural types (Qz1, Qz2, Qz3 and Qz4) by scanning electron microscopy-cathodoluminescence images. In the more preserved rocks of the Younger São Jorge Jovem granite, rich in amphibole and biotite (associations 1 and 2), anhedral crystals of magmatic quartz with high to moderate luminescence $(Q z 1)$ dominate. In the partly altered rocks (associations 2 and 3), post-magmatic to hydrothermal fluids affected the granite, and filled fractures in $Q z 1$ and crystallized not luminescent (dark) Qz2. In the most intensely altered rocks (association 4), successive alteration, dissolution and recrystallization processes gave rise to typically hydrothermal zoned, subhedral (Qz3) and euhedral (Qz4) quartz crystals. Images by backscattered electrons and semiquantitative analysis by energy dispersive spectroscopy identified two generations of gold: Au1, enriched in $\mathrm{Ag}$ (4.3 to 23.7\%) and associated to pyrite crystals; $A u 2$, enriched in Te (1.1 to 17.2\%) and included or associated to Qz4. The scanning electron microscopy-cathodoluminescence study provided important information that was preserved in the quartz structure. The morphological and textural evolution of this mineral in different stages shows the gradual action of the hydrothermalism in the rocks and minerals associations of São Jorge deposit. Gold mineralization of the deposit was chemically (energy dispersive spectroscopy) and paragenetically (pyrite, sphalerite and Qz4) characterized, and it can be divided into different generations or mineralizing events. The effectiveness of the methodology used in this study was established, allowing its application in studies of other hydrothermal deposits.
\end{abstract}

KEYWORDS: Tapajós; SEM; Cathodoluminescence; Quartz; Gold.

\footnotetext{
${ }^{1}$ Programa de Pós-Graduação em Geologia e Geoquímica, Instituto de Geociências, Universidade Federal do Pará - UFPA, Belém (PA), Brasil. E-mail: aldemir.sotero@hotmail.com

${ }^{2}$ Grupo de Pesquisa Petrologia de Granitóides, Instituto de Geociências, Universidade Federal do Pará - UFPA, Belém (PA), Brasil. E-mail: lamarao@ufpa.br gisageo15@yahoo.com.br; psoares29@hotmail.com

*Autor correspondente
}

Manuscrito ID: 20150011. Recebido em: 22/06/2015. Aprovado em: 25/10/2015 


\section{INTRODUÇÃO}

O Granito São Jorge (GSJ), localizado no município de Vila Riozinho, sudoeste do estado do Pará, está inserido no contexto da Província Aurífera do Tapajós (Faraco et al. 1997), a qual ocupa parte das províncias geocronológicas Ventuari-Tapajós e Amazônia Central (Tassinari \& Macambira 1999, 2004). O GSJ é composto pelos granitos São Jorge Antigo (GSJA), com idades de cristalização de $1981 \pm 9 \mathrm{Ma}$ e $1981 \pm 2 \mathrm{Ma}$, e São Jorge Jovem (GSJJ), intrusivo no anterior e com idade de $1891 \pm 3 \mathrm{Ma}$ (Lamarão et al. 2002, 2005). O depósito de ouro São Jorge (SJ) está hospedado em anfibólio-biotita monzogranitos hidrotermalizados em diferentes intensidades, que constituem com biotita leucomonzogranitos, o GSJJ. O depósito SJ foi alvo de prospecção mineral em meados de 1990 pela empresa Rio Tinto Desenvolvimentos Minerais Ltda. (RTDM). Em 2013, a empresa mineradora Brazil Resources passou a deter os direitos econômicos sobre o depósito São Jorge e divulgou um relatório técnico com reserva estimada da ordem de 14,4 milhóes de toneladas, com teor de $1,5 \mathrm{~g} / \mathrm{t} \mathrm{Au}$, o equivalente a 715 mil onças de ouro. As reservas inferidas são de 28,1 milhóes de toneladas com teor de $1,1 \mathrm{~g} / \mathrm{t} \mathrm{Au}$, a um teor de corte de 0,3 g/t Au.

$\mathrm{Na}$ área do depósito SJ, Borges et al. (2009) definiram quatro associaçóes minerais que representam os diferentes estágios de evolução de suas rochas, sendo: a Associação 1, formada no estágio magmático, corresponde às rochas preservadas; a Associação 2 representa o estágio de alteração pós-magmática precoce, com rochas modificadas e intensa saussuritização do plagioclásio; a Associação 3 é representada por rochas hidrotermalizadas; e a Associação 4 é representada por rochas hidrotermalizadas e mineralizadas. Nos furos FSJ-02 e FSJ-06, as rochas do GSJJ encontram-se intensamente hidrotermalizadas e com mineralizaçóes de sulfetos (pirita, calcopirita, esfalerita e galena) e ouro. No furo FSJ-04, também se mostram parcialmente hidrotermalizadas e mineralizadas, enquanto as rochas do furo FSJ-09, pouco afetadas pelos processos hidrotermais, apresentam rara ou nenhuma mineralização associada.

O estudo morfológico e composicional de quartzo em rochas ígneas utilizando microscopia eletrônica de varredura-catodoluminescência (MEV-CL) tem se tornado uma metodologia complementar importante para o entendimento da história de cristalização e das condições envolvidas durante a formação desse mineral (D'Lemos et al. 1997; Müller et al. 2000, 2003, 2005; Landtwing \& Pettke 2005; Wiebe et al. 2007; Breiter \& Müller 2009; Larsen et al. 2009). Zoneamentos composicionais, defeitos intracristalinos, reabsorçôes, alteraçôes, dilataçôes de cristais e fraturas preenchidas, são feições texturais importantes que podem ser observadas apenas com o auxílio de MEV-CL (Loomis \& Welber 1982; Hogan 1993; Müller et al. 2000, 2002, 2005; Rusk \& Reed 2002; Rusk et al. 2008; Slaby et al. 2008). A CL também tem sido utilizada para distinguir diferentes geraçóes de quartzo dentro de uma mesma unidade magmática, podendo revelar diferentes processos magmáticos envolvidos, como a história da evolução e cristalização de magmas, relaçôes entre cristais-inclusões fluidas, estágios de deformação e alteração, além de possibilitar a identificação de quartzo hidrotermal dentro de um depósito mineral e sua eventual relação aos processos metalogenéticos (Rusk \& Reed 2002; Müller et al. 2005; Rusk et al. 2006, 2008; Larsen et al. 2009; Vasyukova et al. 2013; Lamarão et al. 2013, 2014).

Nesse contexto, o principal objetivo desse estudo é estabelecer a evolução morfológica e textural de cristais de quartzo presentes nas rochas do GSJJ (área do depósito São Jorge) através de MEV-CL, e sua correlação com a intensidade da alteração hidrotermal, as geraçôes de ouro quimicamente distintas (por EDS - Energy Dispersive Spectroscopy) e os principais sulfetos associados (pirita e esfalerita).

\section{CONTEXTO GEOLÓGICO REGIONAL}

A Província Aurífera do Tapajós (PAT) (Faraco et al. 1997; Juliani et al. 2002) está localizada a sudoeste do estado do Pará, no limite com o estado do Amazonas, e abrange uma área de aproximadamente $140.000 \mathrm{~km}^{2}$ no Cráton Amazônico (Fig. 1A). Ocupa parte da província geocronológica Ventuari-Tapajós (Tassinari \& Macambira 1999, 2004) e é constituída dominantemente por rochas plutônicas e vulcânicas paleoproterozoicas intermediárias a félsicas, de afinidades cálcico-alcalina e alcalina (Klein \& Vasquez 2000; Vasquez et al. 2002; Lamarão et al. 2002; Lamarão \& Dall'Agnol 2002).

O embasamento da PAT é formado principalmente por xistos pelíticos do Grupo Jacareacanga e ortognaisses tonalíticos e granodioríticos do Complexo Cuiú-Cuiú, além de granodioritos, tonalitos e pequenas ocorrências de monzogranitos e dioritos cálcico-alcalinos (Pessoa et al. 1977; Melo et al. 1980; Ferreira et al. 2000; Klein \& Vasquez 2000; Vasquez \& Klein 2000; Klein et al. 2001; Juliani et al. 2002; Vasquez et al. 2008). Santos et al. (2001) obtiveram idades U-Pb em zircão de $2033 \pm 7$ e $2011 \pm 23$ Ma para granodiorito e tonalito desse complexo. Sequências metavulcanossedimentares do Grupo Jacareacanga, com idade em zircôes detríticos variando de 2100 a $2875 \mathrm{Ma}$, são consideradas contemporâneas ao Complexo Cuiú-Cuiú, e ambos representariam o estágio inicial de desenvolvimento de um 
arco magmático (Ferreira et al. 2000; Klein \& Vasquez 2000; Santos et al. 2000; Klein et al. 2001).

Seguindo na sequência estratigráfica da província, ocorrem rochas vulcânicas de 2,0 Ga compostas por andesitos basálticos, traquiandesitos basálticos, traquitos e riolitos da Formação Vila Riozinho (Lamarão et al. 2002, 2005) e granitoides cálcico-alcalinos sin a tardi-tectônicos com 1,96 a 2,0 Ga pertencentes à Suíte Creporizão (Ricci et al. 1999; Santos et al. 2000; Lamarão et al. 2002). A Suíte Parauarí, com idade entre 1,89 e 1,87 Ga, representa a geraçáo mais jovem de granitos cálcico-alcalinos pós-orogênicos da PAT (Klein \& Vasquez 2000; Santos et al. 2000; Lamarão et al.
2002; Vasquez et al. 2002). Por volta de 1,88 Ga, um volumoso magmatismo granítico tipo A ocorreu na PAT e foi agrupado nas Suítes Maloquinha e Caroçal. Sequências vulcânicas intermediárias a félsicas, com idades entre 1890 e 1875 Ma pertencentes às Formaçóes Moraes Almeida e Bom Jardim, foram agrupadas no Grupo Iriri, do Supergrupo Uatumã (Klein \& Vasquez 2000; Klein et al. 2001; Lamarão \& Dall'Agnol 2002; Lamarão et al. 2002, 2005). Intrusóes de corpos máficos a intermediários (Suítes Ingarana e Cachoeira Seca), além de diques máficos (Diabásio Crepori) e lamprófiros, completam o magmatismo da PAT (Quadros et al. 1999; Santos et al. 2001).

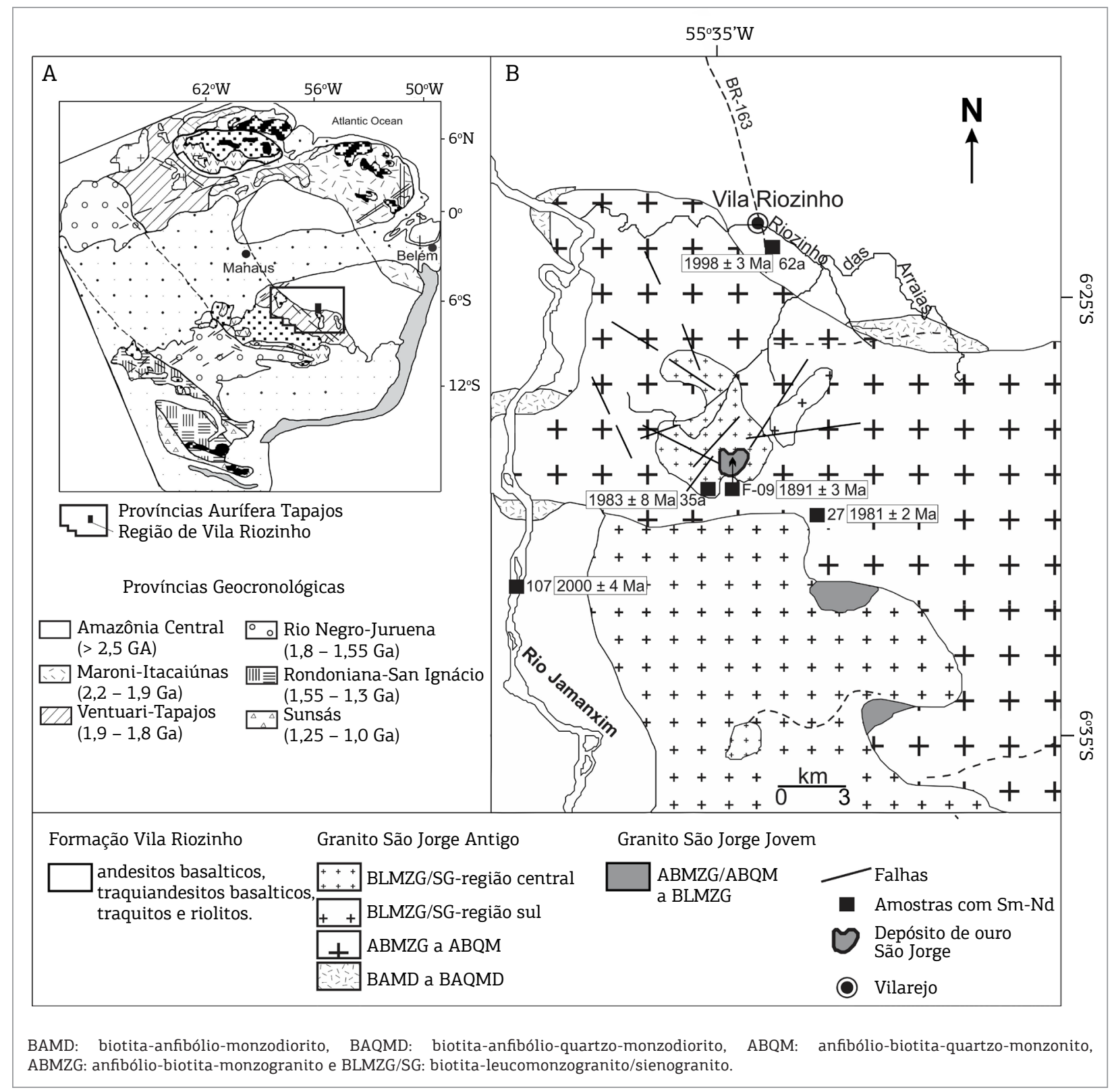

Figura 1. (A) Províncias geocronológicas do Cráton Amazônico (Tassinari \& Macambira 2004); (B) Mapa geológico da região de Vila Riozinho e do Granito São Jorge (modificado de Lamarão et al. 2002). 


\section{GRANITO SÃO JORGE}

O Granito São Jorge está situado no município de Vila Riozinho, porção central da Província Aurífera do Tapajós, sudoeste do estado do Pará. Ele é formado pelos granitos São Jorge Antigo e São Jorge Jovem. O GSJA é um batólito irregular, constituído por rochas maciças isotrópicas acinzentadas, representadas por biotita-anfibólio-monzodiorito a quartzo-monzodiorito (BAMD a BAQMD) aflorantes nas bordas NE, NW e W, anfibólio-biotita-monzogranito (dominantes) a quartzo-monzonito (ABMZG a ABQM) aflorantes nas porçóes mais centrais, anfibólio-biotita-quartzosienito $(A B Q S)$ e biotita-leucomonzogranito-sienogranitos (BLMG/SG) que ocorrem na parte central (Fig. 1B). A disposição das rochas mais máficas, aflorando nas bordas, e as mais félsicas, na parte central, sugere que o corpo é composicionalmente zonado. Mineralogicamente, o GSJA contém cristais médios a grossos de plagioclásio e feldspato potássico, cristais médios a finos de quartzo, anfibólio e biotita. As fases minerais acessórias dominantes são zircão, apatita, titanita, allanita e opacos. Epidoto, clorita, titanita e sericita são as principais fases secundárias. Dataçôes $\mathrm{Pb}-\mathrm{Pb}$ em zircão em ABMZG forneceram idades de $1981 \pm 2$ e $1983 \pm$ $8 \mathrm{Ma}$, consideradas idades de cristalização (Lamarão et al. 2002, 2008).

O GSJJ aflora na porção sul do GSJ na forma de blocos hidrotermalizados de coloração avermelhada. $\mathrm{Na}$ área do depósito SJ, o GSJJ foi identificado por meio de testemunhos de sondagem. Segundo Lamarão et al. (2002), dominam anfibólio-biotita-monzogranitos a quartzo-monzonitos (ABMZG a ABQM) e biotita-leucomonzogranitos (BLMZG) hospedeiros da mineralização aurífera do depósito São Jorge. As rochas do GSJJ são mineralógica e texturalmente similares às rochas equivalentes do GSJA. Datação $\mathrm{Pb}-\mathrm{Pb}$ em zircão em rochas leucomonzograníticas revelou idade de cristalização de $1891 \pm 3$ Ma para o GSJJ.

\section{Aspectos petrográficos}

As descriçóes a seguir envolvem as quatro associaçóes minerais propostas por Borges et al. (2009) para as rochas da área do depósito SJ, baseadas na intensidade da alteração hidrotermal atuante no corpo.

- Associação 1 - corresponde às rochas menos evoluídas, pouco alteradas e isentas de mineralizaçáo do GSJJ. A rocha é um anfibólio-biotita-monzogranito isotrópico, de granulação média a grossa, coloração rosada a cinza rosada, com textura granular ainda bem preservada (Fig. 2A). Em algumas porções ocorrem veios aplíticos, enclaves máficos e textura rapakivi. A composição mineralógica é representada essencialmente por feldspato alcalino, quartzo e plagioclásio (An32-12) com zoneamento marcante e fraca saussuritização; biotita levemente cloritizada e actnolita compóem as principais fases varietais (Fig. 3A-B). Os minerais acessórios comuns são opacos, titanita, zircão e apatita.

- Associação 2 - a rocha apresenta indícios de alteração pós-magmática precoce e coloração mais avermelhada (Fig. 2B-C). Algumas porçôes da rocha contêm fraturas e veios, porém com textura ígnea ainda preservada e sem mineralização associada. Biotita e anfibólio ainda estão presentes, porém o anfibólio ocorre pseudomorfisado (Fig. 3C) e parcialmente substituído por clorita, carbonatos, óxidos de Fe e $\mathrm{Ti}$, titanita e epidoto; a biotita ocorre parcialmente cloritizada. O plagioclásio ocorre intensamente saussuritizado (Fig. 3D). Feldspato alcalino, com maclas albita-periclina, titanita e minerais opacos primários encontram-se ainda preservados.

- Associação 3 - representa porçóes de rochas hidrotermalizadas, com coloração avermelhada e pontos esverdeados (Fig. 2D). O plagioclásio ocorre intensamente saussuritizado e descalcificado, substituído por mica branca e carbonato. $\mathrm{O}$ anfibólio encontra-se totalmente substituído por clorita e epidoto, enquanto a biotita sofre alteraçáo intensa para clorita (Fig. 3E a 3G). O quartzo preenche veios e vênulas que cortam a rocha. Titanita, magnetita e ilmenita mostram corrosão e substituição por opacos. Essa associação representa o estágio de alteração propilítica e o início dos processos hidrotermais que geraram a mineralização no GSJJ.

Associação 4 - corresponde à porção mais alterada do granito, com feiçôes texturais e mineralógicas totalmente obliteradas; a rocha assume coloração rosa esverdeada a verde rosada, apresenta porçóes brechadas cortadas por veios (Fig. 2E-F) e zonas mineralizadas em sulfetos e ouro. O plagioclásio original sofre intensa descalcificação, passa a apresentar composição albítica e ocorre impregnado por mica branca e carbonato (Fig. 3F). Essa associação representa o ápice da alteração hidrotermal, com intensa alteração fílica, caracterizada por conteúdos expressivos de mica branca, carbonato e sulfetos, principalmente pirita (Fig. 3H-I). Os sulfetos ocorrem preenchendo fraturas ou associados a quartzo, clorita e carbonato. O ouro ocorre como finas inclusóes em cristais de pirita, esfalerita e quartzo.

\section{METODOLOGIA}

Foram utilizadas 47 lâminas polidas (Tab. 1) representativas das associaçóes minerais 1, 2, 3 e 4, propostas por Borges et al. (2009), confeccionadas a partir dos testemunhos de sondagem dos furos FSJ-02, FSJ-04, FSJ-06 
e FSJ-09, executados no GSJJ. Inicialmente, foi realizado um estudo petrográfico por luz transmitida, com a obtenção de fotomicrografias dessas associaçôes minerais e dos principais tipos de quartzo presentes nelas, utilizando-se um microscópio Leica DM 2500 P com câmera acoplada, pertencente ao Instituto de Geociências da Universidade Federal de Pará (IG-UFPA). As lâminas selecionadas foram metalizadas com carbono para imageamento de quartzo por elétrons retroespalhados (ERE), catodoluminescência (CL) e análises por EDS (Energy Dispersive Spectroscopy). O MEV utilizado foi um LEO-ZEISS 1430 do IG-UFPA com sistema de Mono-CL Gatan e detector de EDS Sirius-SD acoplados. As condições de operação para o imageamento de quartzo em CL foram: corrente do feixe de elétrons = $90 \mu \mathrm{a}$, voltagem de aceleração de 10 KV e distância de trabalho de $13 \mathrm{~mm}$. Para a obtenção de imagens de ERE e análises por EDS, foram utilizadas corrente do feixe de elétrons $=90 \mu \mathrm{a}$, voltagem de aceleração constante $=20 \mathrm{KV}$, distância de trabalho $=15 \mathrm{~mm}$, tempo de análise $=30 \mathrm{~s}$, com 4.000 a $5.000 \mathrm{c} / \mathrm{s}$ para cada análise. Análises semiquantitativas por EDS foram realizadas para a identificação de partículas de ouro e sulfetos, além de outras fases acessórias. Os principais elementos analisados foram $\mathrm{O}, \mathrm{Si}, \mathrm{Fe}, \mathrm{Cu}, \mathrm{Au}, \mathrm{Bi}, \mathrm{Te}, \mathrm{Ag}, \mathrm{As}, \mathrm{Ba}$ e Zn. As análises por EDS utilizaram o padrão $\mathrm{ZAF}\left(\mathrm{Z}=\mathrm{n}^{\mathrm{o}}\right.$ atômico, $\mathrm{A}=$ absorção atômica e $\mathrm{F}$ = fluorescência de raios $\mathrm{X}$ ) para correçóes entre picos e backgrounds dos elementos.

\section{Aplicações de microscopia eletrônica de varredura-catodoluminescência em quartzo}

Estudos de quartzo por MEV-CL com finalidades metalogenéticas são relativamente raros. Rusk e Reed (2002) utilizaram dados de MEV-CL e inclusóes fluidas de veios mineralizados do depósito de cobre pórfiro de Butte-Montana. Os autores identificaram cristais de quartzo luminescentes associados à molibdenita e cristais de quartzo zonados
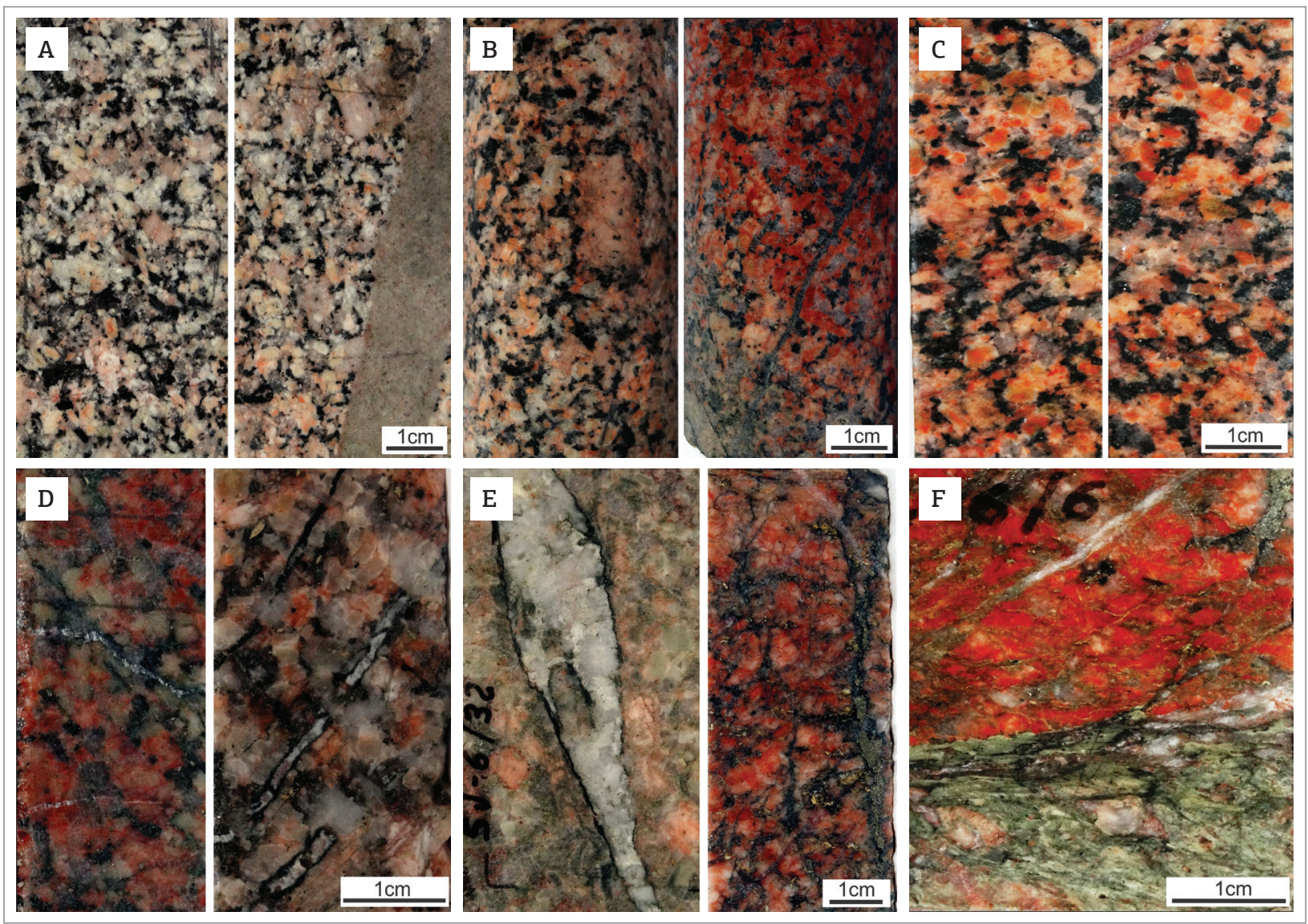

Figura 2. Imagens macroscópicas de amostras dos furos de sondagem do Granito São Jorge Jovem, correspondentes às associações minerais de Borges et al. (2009). (A) associação 1 - rocha granítica com textura ígnea preservada e presença de veios aplíticos de espessura centimétrica; (B e C) associação 2 - rocha pouco alterada com coloração mais avermelhada; (D) associação 3 - rocha hidrotermalizada, contendo vênulas e veios de quartzo, pobremente mineralizada; (E e F) associação 4 - rocha intensamente hidrotermalizada/mineralizada, com porções avermelhadas ou esverdeadas, cortada por veios centimétricos de quartzo. 
associados à pirita. Texturas presentes no quartzo foram interpretadas como produto da variação da solubilidade de sílica em fluidos hidrotermais e da variação de temperatura e pressão relacionadas à mineralização da rocha hospedeira do depósito. Rusk et al. (2008), através de imagens de CL e de análises de LA-ICP-MS, observaram que depósitos de cobre pórfiro de alta temperatura $\left(500-700{ }^{\circ} \mathrm{C}\right)$ apresentam cristais de quartzo com concentraçóes elevadas de Ti
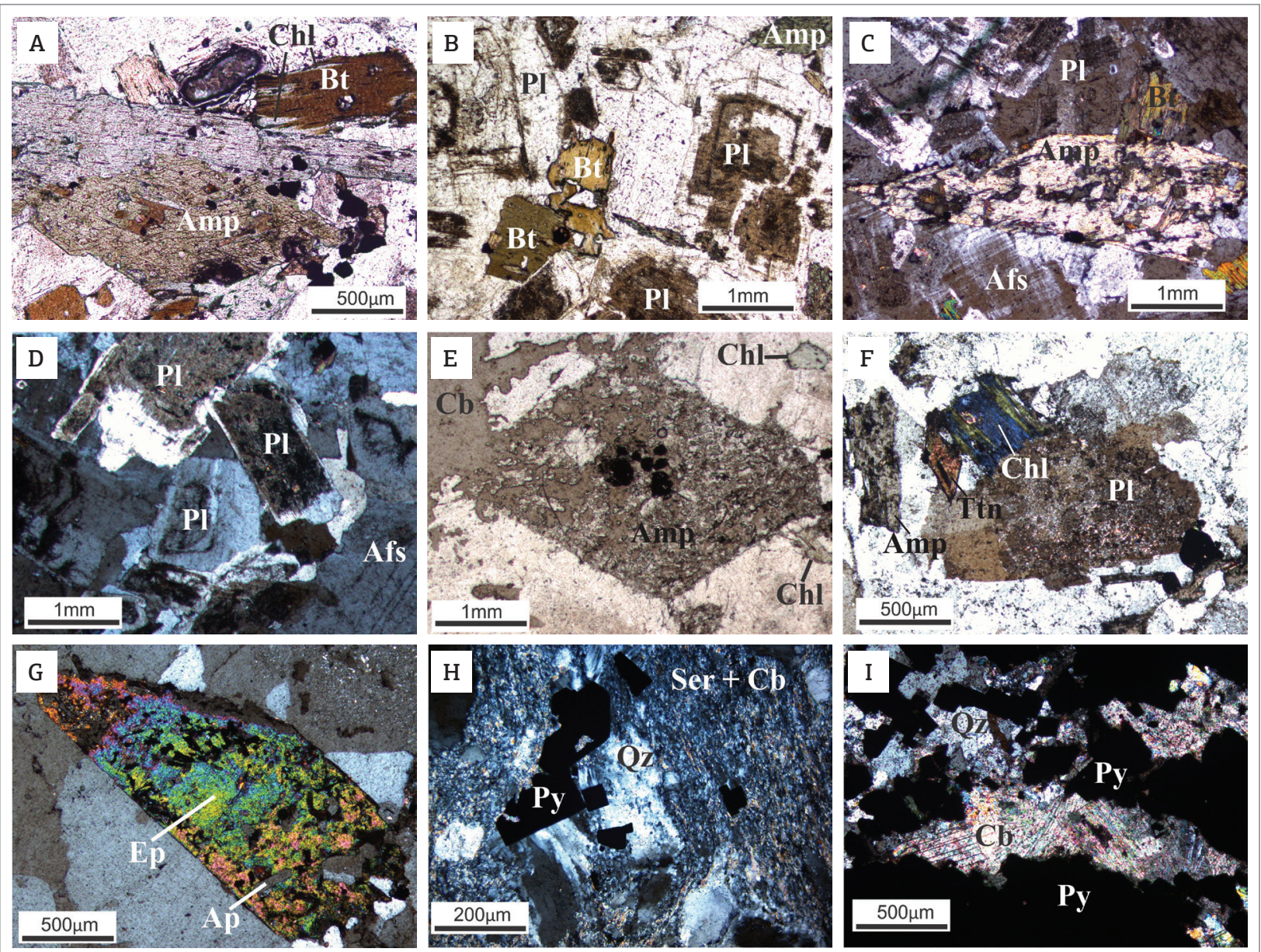

Afs: feldspato alcalino, Amp: anfibólio, Ap: apatita, Bt: biotita, Cb: carbonato, Chl: clorita, Ep: epidoto, Pl: plagioclásio, Py: pirita, Qz: quartzo e Ser: sericita. Abreviações segundo Whitney \& Evans (2010).

Figura 3. Fotomicrografias mostrando feições mineralógico-texturais das diferentes associações minerais do Granito São Jorge Jovem. (A e B) Associação 1. Cristais euédricos a subédricos de hornblenda verde-clara, contendo inclusões de minerais opacos e apatita; biotita marrom levemente alterada para clorita e cristais de plagioclásio zonados associados à biotita e anfibólio. (C e D) Associação 2. Anfibólio pseudomorfisado associado a plagioclásio saussuritizado e feldspato alcalino. (E a G) Associação 3. Alteração propilítica, com anfibólio substituído por clorita, carbonato e epidoto; biotita cloritizada, plagioclásio sericitizado e titanita ainda presente. (H e I) Associação 4. Alteração fílica, com plagioclásio substituído por sericita e carbonato; cristais de pirita associados com quartzo e carbonato.

Tabela 1. Lâminas polidas utilizadas nesse estudo com as respectivas associações minerais atribuídas.

\begin{tabular}{l|c}
\hline $\begin{array}{l}\text { Associações minerais } \\
\text { (Borges et al. 2009) }\end{array}$ & Lâminas polidas \\
\hline 1 & FSJ-04-22, FSJ-04-25, FSJ-04-29, FSJ-04-38, FSJ-09-01, FSJ-09-08, FSJ-09-09, FSJ-09-10, FSJ-09-12, \\
FSJ-09-13, FSJ-09-17.
\end{tabular}

FSJ: Furo São Jorge 
(200 - 450 ppm) em correlação positiva com a catodoluminescência; por outro lado, em depósitos epitermais de ouro e prata $\left(100-300^{\circ} \mathrm{C}\right)$, o quartzo apresenta fraca luminescência e baixos conteúdos de Ti ( $\leq 200$ ppm).

Lamarão et al. (2013) mostraram que o quartzo foi um excelente marcador da evolução magmática e das alteraçóes hidrotermais que atuaram no Granito Antônio Vicente, Província Estanífera do Sul do Pará, e em greisens associados. Cinco tipos de quartzo foram identificados, sendo um magmático e quatro hidrotermais. A mineralização estanífera acompanha as rochas mais evoluídas e alteradas hidrotermalmente e os greisens, ocorrendo associada ou inclusa nos quartzos hidrotermais. Lamarão et al. (2014), utilizando imagens de MEV-CL, correlacionaram cristais de quartzo de diferentes unidades vulcânicas e plutônicas das províncias Aurífera do Tapajós e Estanífera do Xingu, cráton Amazônico, além de estabelecerem relaçóes cronológicas entre diferentes eventos de mineralização em greisens da Província Estanífera de Pitinga, Amazonas, e em arenitos do Grupo Serra Grande, Bacia do Parnaíba, portadores de veios de opala laranja e quartzo.

\section{ANÁLISE MORFOLÓGICA DE QUARTZO}

\section{Estudo por luz transmitida}

Com base em aspectos morfológico-texturais e no aumento da alteração hidrotermal, foram individualizados três tipos principais de quartzo. O Tipo-1, dominante nas associaçóes 1 e 2, representa o quartzo magmático; forma cristais anédricos médios a grossos com extinção ondulante incipiente; desenvolve contatos irregulares com plagioclásio, feldspato alcalino, anfibólio, biotita e titanita (Fig. 4A a 4C). O Tipo-2 domina nas associaçôes 3 e 4, onde forma cristais subédricos a anédricos médios a grossos com extinção ondulante forte; ocorre formando vênulas, veios e bolsóes mineralizados com pirita, calcopirita e ouro, ou associado a carbonatos e micas brancas (Fig. 4D a 4F). O Tipo-3 foi identificado somente nas porçóes mais alteradas $\mathrm{da}$ associação 4 , onde a rocha se encontra intensamente hidrotermalizada e mineralizada; apresenta-se como cristais euédricos bipiramidais, de granulação fina a média (Fig. 4G a 4I).

\section{Estudo por catodoluminescência}

Imagens por $\mathrm{CL}$ revelaram zoneamentos composicionais, cristais reabsorvidos, fraturas preenchidas e outras feiçóes intracristalinas, as quais permitiram distinguir cristais de quartzo magmático e hidrotermal no GSJJ. A intensidade de luminescência absoluta no quartzo não pode ser quantificada facilmente, pois a luminescência aparente observada nas imagens por CL depende das condiçôes operacionais (Rusk \& Reed 2002). Assim, nas descriçōes a seguir a intensidade de luminescência em CL é referida como tons de cinza, ou seja, baixa luminescência (cor cinza escura), luminescência moderada (cor cinza) e alta luminescência (cor cinza clara). Os cristais de quartzo foram estudados de acordo com a intensidade da alteração hidrotermal e a mineralização presente na rocha. Foram identificadas quatro diferentes geraçóes de quartzo $(\mathrm{Q} z 1, \mathrm{Qz2}, \mathrm{Qz3}$ e Qz4), descritas a seguir:

- Qz1 - ocorre dominantemente nas associaçóes minerais 1 e 2; forma cristais anédricos preservados a fracamente fraturados, com luminescência moderada a alta (coloração cinza clara, Fig. 5A); associa-se a plagioclásio, anfibólio, biotita e titanita euédrica, e corresponde ao quartzo Tipo-1 definido em microscopia de luz transmitida. Também está presente nas associações 3 e 4, porém, nesse caso, se mostra intensamente fraturado e brechado (Fig. 5B-C), com bordas corroídas e dissolvidas.

Qz2 - posterior ao Qz1, é representado por vênulas de baixa luminescência (coloraçáo cinza escura) que preenchem fraturas e seccionam o Qz1 (Fig. 5B). Ocorre na associação 2 e se intensifica nas associaçóes 3 e 4, associado à pirita (Fig. 5C). Essa geração de quartzo foi identificada apenas por imagens de CL, não tendo correspondente em luz transmitida.

- Qz3 - ocorre em veios e bolsóes mineralizados (quartzo Tipo-2 em luz transmitida); é subédrico a anédrico, apresenta zoneamento parcial com alternância entre porçóes mais e menos luminescentes (Fig. 5D a 5F); está presente na associação 4 com cristais de pirita e esfalerita, e mais raramente calcopirita e galena; nessa porção da rocha, o ouro ocorre principalmente preenchendo fraturas na pirita ou incluso na esfalerita.

- Qz4 - representa a geração mais tardia, ocorre nas porçôes de rocha mais intensamente alteradas e mineralizadas a ouro; forma cristais euédricos finos a médios com zoneamento bem definido, alternando zonas escuras e luminescentes de espessura fina, comumente inclusos em carbonatos ou sericita, ou em contato com estes (Fig. 5G a 5I). Corresponde ao quartzo do Tipo-3 em luz transmitida.

\section{ANÁLISES QUÍMICAS DO OURO POR ENERGY DISPERSIVE SPECTROSCOPY}

Nas associaçóes minerais 1 e 2, onde ocorrem Qz1 e Qz2, as rochas são preservadas e sem mineralizaçáo associada. Nas associaçôes minerais 3 e 4, onde as rochas estão 
intensamente hidrotermalizadas e mineralizadas, principalmente com pirita, esfalerita e ouro, Qz3 e Qz4 são dominantes. O ouro, frequente nas rochas mais hidrotermalizadas da associação 4, ocorre incluso ou preenchendo fraturas na pirita e esfalerita (Fig. 6) ou associados ao Qz4 (Fig. 7).

Considerando as relaçóes texturais entre ouro, pirita e quartzo observadas em imagens de ERE e CL, assim como as análises químicas realizadas por EDS (Tab. 2), foram identificadas duas geraçóes de ouro quimicamente distintas: Au 1, correspondente ao ouro associado à pirita; $\mathrm{Au} 2$, correspondente ao ouro associado ao Qz4 e/ou incluso na esfalerita. As análises das partículas de Au1 por EDS mostram teores elevados e variáveis de prata $(4,3-23,7 \%)$, com exceção de uma análise $(1,1 \%)$, baixos teores de telúrio $(0,2-1,2 \%)$ e, consequentemente, razóes $\mathrm{Au} / \mathrm{Ag}$ e $\mathrm{Au} / \mathrm{Te}$ mais baixas e mais elevadas, respectivamente. $\mathrm{O} A u 2$ apresenta composição química distinta do Au1, com baixos teores de prata $(<1,0 \%)$, altos e variáveis teores de telúrio $(1,1-17,2 \%)$ e razóes $\mathrm{Au} / \mathrm{Ag} \mathrm{e} \mathrm{Au} / \mathrm{Te}$ inversas àquelas do Au1. Nesse contexto, a mineralizaçáo aurífera do depósito SJ seria marcada por dois eventos: o primeiro, com a deposição do ouro Au1 enriquecido em Ag e associado à pirita; e o segundo correspondente ao ouro Au2, com teores elevados de Te e associado ao Qz4 e à esfalerita.

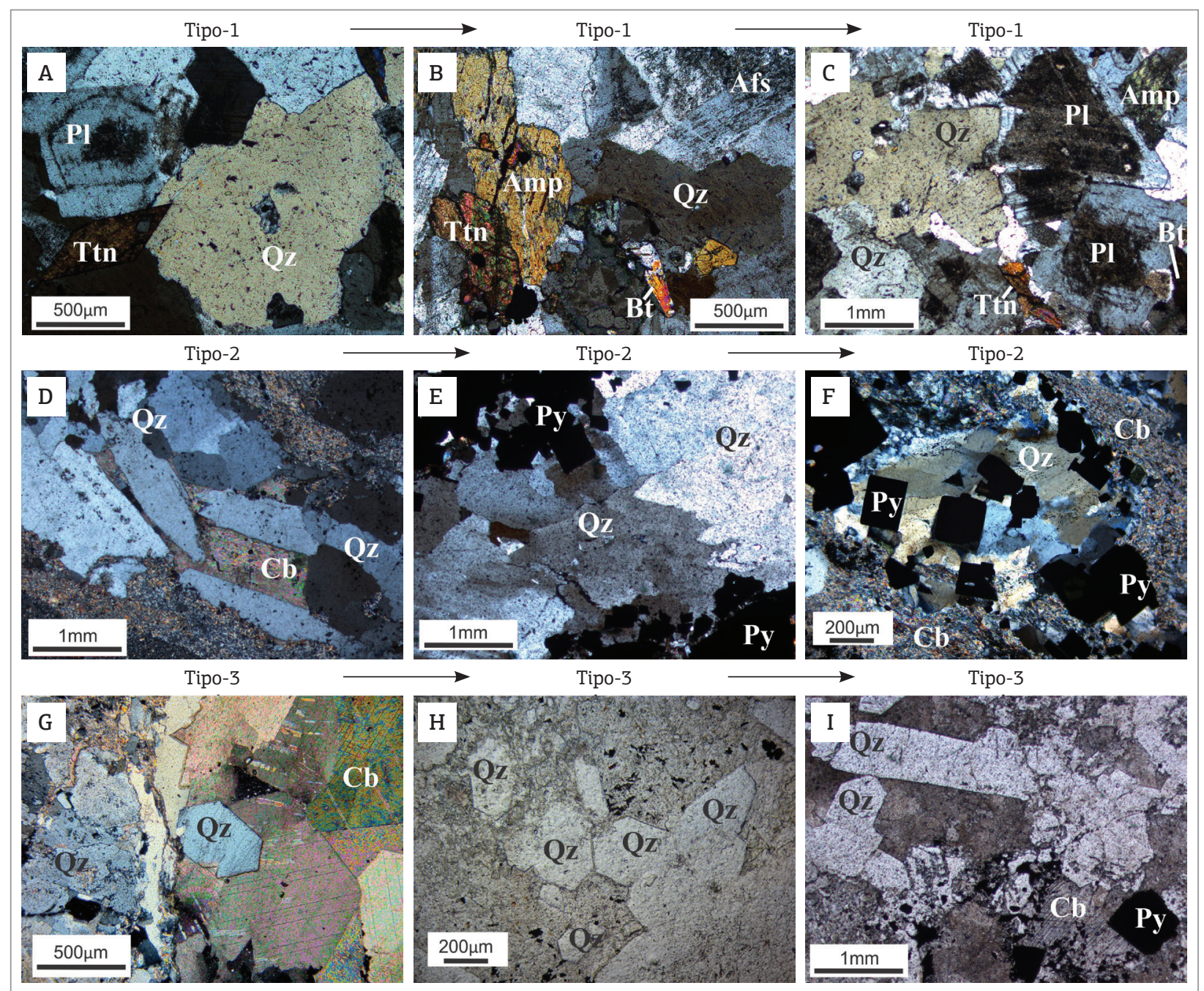

Afs: feldspato potássico, Amp: anfibólio, Bt: biotita, Cb: carbonato, Pl: plagioclásio, Py: pirita, Qz: quartzo e Ttn: titanita. Seta: aumento da intensidade de alteração da rocha. Abreviações segundo Whitney \& Evans (2010).

Figura 4. Fotomicrografias de quartzo em luz transmitida (nicóis cruzados e paralelos). (A) Quartzo tipo-1, magmático, associado a plagioclásio zonado e titanita euédrica (Associação 1). (B e C) Quartzo Tipo-1 associado com plagioclásio saussuritizado e finos cristais de anfibólio, biotita e titanita (Associação 2). (D a F) Quartzo Tipo-2, apresentando cristais subédricos médios a grossos com extinção ondulante forte; forma vênulas, veios ou bolsões mineralizados (principalmente pirita) em contato com cristais de carbonato (Associações 3 e 4). (G a I) Quartzo Tipo-3 euédrico, incluso em carbonato ou associado à pirita. 


\section{DISCUSSÕES}

\section{Texturas em catodoluminescência}

Dissoluçáo de quartzo luminescente, intercrescimento de quartzo escuro, dilatação de cristais, recristalização e zoneamentos, são exemplos de texturas que podem ser observadas por CL. Texturas como zonas de crescimento presentes no quartzo podem indicar diversas geraçóes de inclusóes fluidas ou "demarcar" específicos episódios de mineralização, podendo ser utilizadas para o estudo de depósitos (Rusk \& Reed 2002; Rusk et al. 2008). Essas texturas podem ser caracterizadas de acordo com variação na luminescência do cristal. A alta luminescência é emitida por cristais de quartzo formados a temperaturas $>400^{\circ} \mathrm{C}$ e que apresentam altas concentraçóes de elementos traços como Ti e Al, principais ativadores da CL nesse mineral (Wark \& Watson 2006; Rusk 2008; Larsen et al. 2009; Vasyukova et al. 2013).
Por meio de análises químicas por Microssonda Eletrônica, Rusk et al. (2008) obtiveram concentraçóes de até 450 ppm de Ti no quartzo presente em veios de depósitos formados sob temperaturas entre 500 e $700^{\circ} \mathrm{C}$; enquanto no quartzo dos depósitos formados entre 100 e $300^{\circ} \mathrm{C}$, as concentraçóes de Ti ficam geralmente em torno de 100 ppm.

$\mathrm{Na}$ área do depósito de ouro São Jorge, a ação de fluidos hidrotermais e as alterações mineralógicas e hidrotermais estão sistematicamente registradas nas rochas do GSJJ (Borges et al. 2009; Borges 2010). As imagens por MEV-CL mostraram que a alteração progressiva do Qz1 e a cristalização de novas geraçóes Qz2, Qz3 e Qz4 certamente foram controladas pela ação desses fluidos e dos processos hidrotermais e mineralizadores dessas rochas. As principais texturas presentes são: faturamento, corrosão e dissolução do quartzo luminescente $(\mathrm{Q} z 1)$; vênulas formadas por quartzo escuro $(\mathrm{Q} z 2)$ que seccionam o $\mathrm{Qz} 1$,
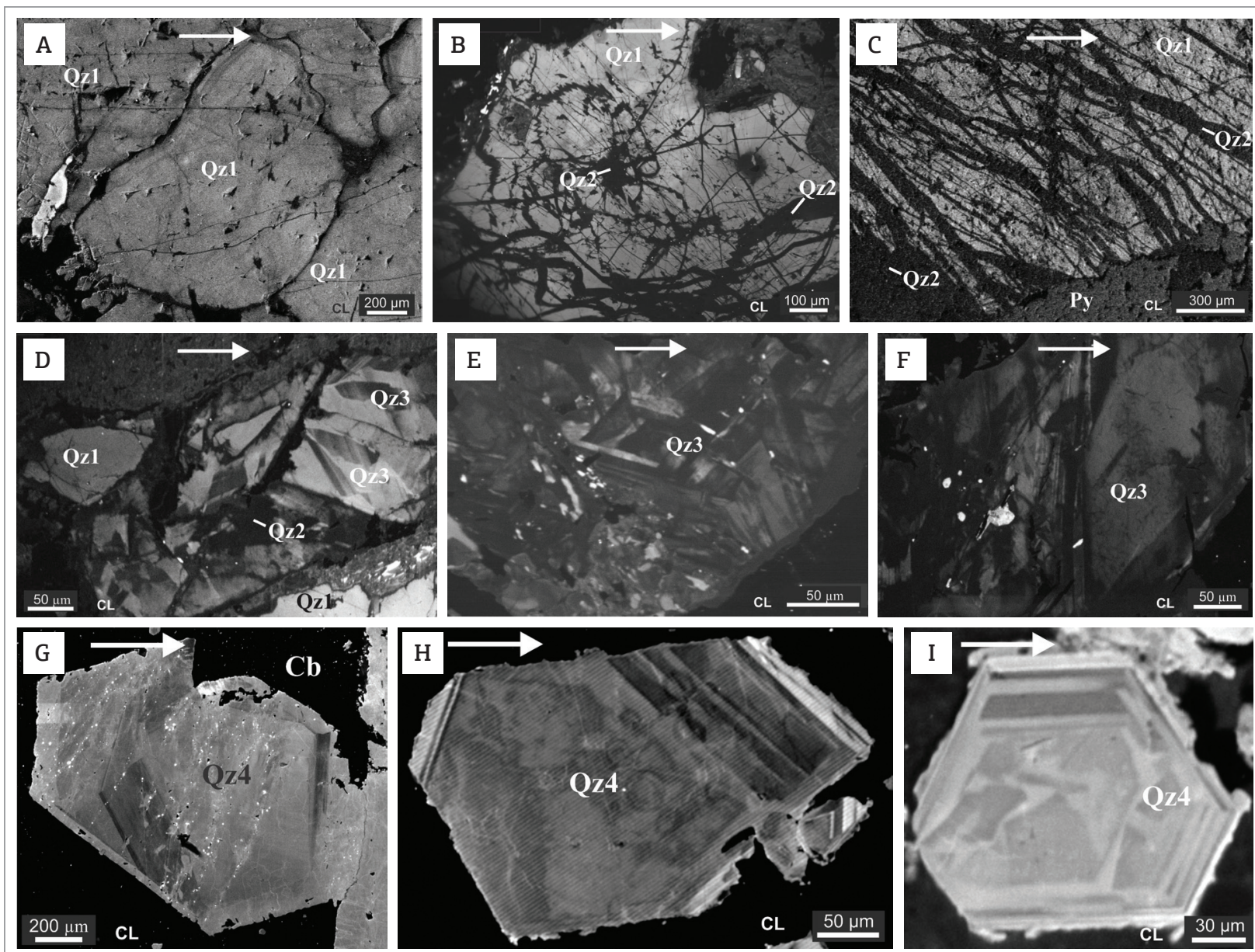

Qz1: magmático, anédrico e luminescente; Qz2: secundário, cinza escuro, pouco luminescente, preenche fraturas e secciona o Qz1; Qz3: hidrotermal, euédrico a subédrico, parcialmente zonado, com núcleos mais luminescentes; Qz4: hidrotermal, euédrico, neoformado, com zoneamento claro-escuro bem definido. $\mathrm{Py}=$ pirita; $\mathrm{Cb}=$ carbonato. Seta = intensidade de alteração na rocha.

Figura 5. (A-I) tipos de quartzo identificados nas rochas do Granito São Jorge Jovem através de imagens de microscopia eletrônica de varredura-catodoluminescência. 

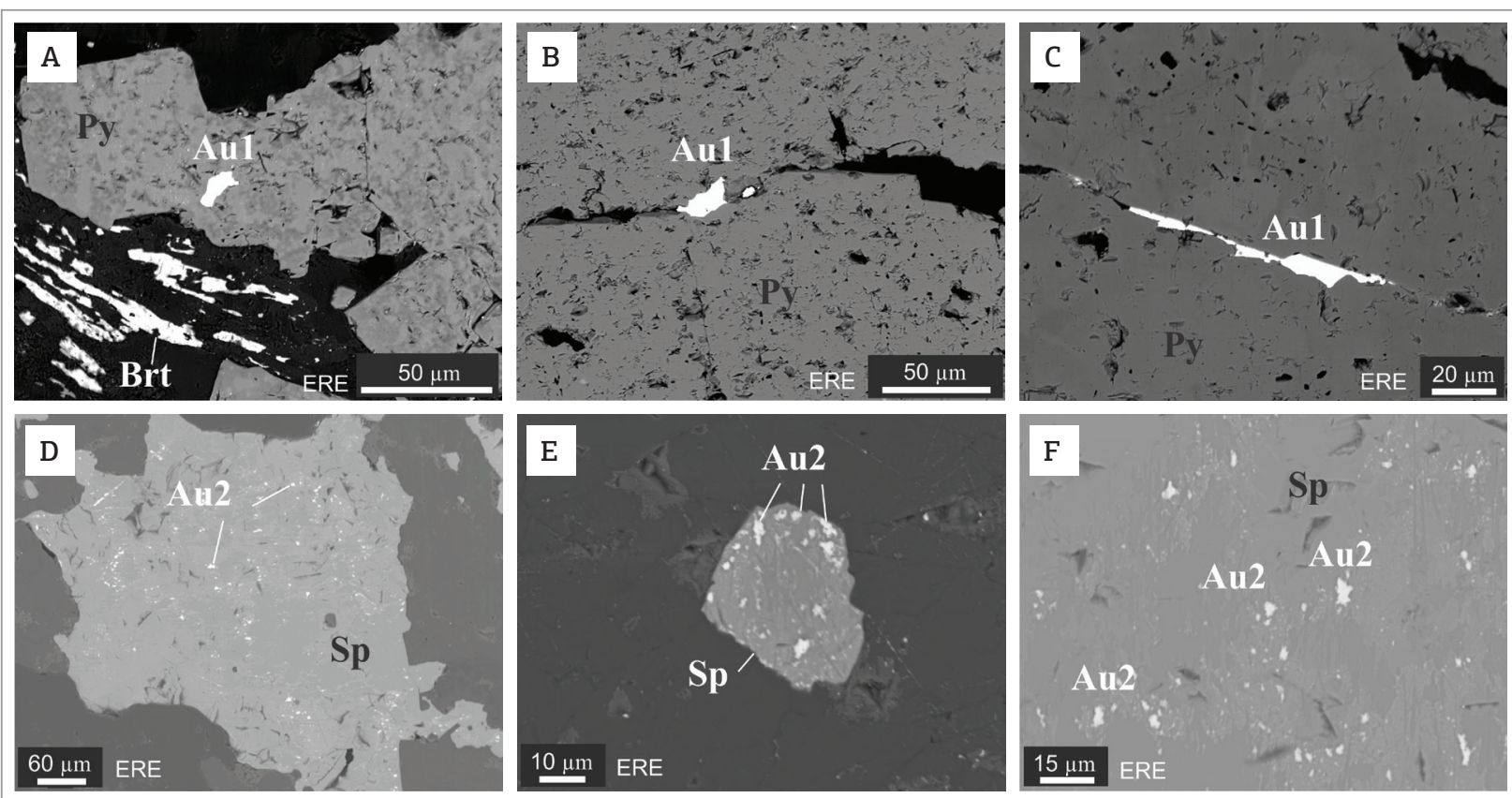

Cb: carbonato, Py: pirita, Sp: esfalerita, Au: ouro, Qz: quartzo, Ccp: calcopirita. Abreviações segundo Whitney \& Evans (2010).

Figura 6. Imagens de elétrons retroespelhado utilizadas nas análises de energy dispersive spectroscopy. (A a C) Primeira geração de ouro (Au1) inclusa ou preenchendo fraturas na pirita. (D a F) Segunda geração de ouro (Au2) hospedada em cristais de esfalerita.

exibindo um aspecto brechóide nos cristais; e zoneamento euédrico em cristais de quartzo hidrotermal (Qz3 e Qz4), caracterizado pela alternância entre zonas de crescimento escuras e claras e interpretado como resultado da reorganização espacial dos elementos traços (provavelmente Ti) na estrutura do cristal. Essas transformaçōes afetaram os cristais de quartzo desde a rocha preservada e estéril até as porçôes intensamente hidrotermalizadas e mineralizadas.

No GSJJ, por exemplo, o quartzo menos luminescente (Qz2) ocorre associado à pirita e constitui grande parte dos veios mineralizados (Fig. 5C), enquanto o quartzo zonado euédrico (Qz4) ocorre associado à esfalerita e ao ouro (Fig. 7). Neste estudo, propóe-se que o Qz1 é de origem magmática, foi formado em altas temperaturas, pois é dominante na associação 1 (magmática) de temperatura $\geq 700^{\circ} \mathrm{C}$, e possivelmente mais enriquecido em Ti do que os demais tipos, em razão de sua alta luminescência. $\mathrm{O} Q \mathrm{Q} 2$ foi formado em temperaturas mais baixas $\left(340-280^{\circ} \mathrm{C}\right.$, associaçóes 3 e 4 onde é dominante), mostra baixa luminescência e, possivelmente, conteúdo de Ti muito baixo. Os quartzos Qz3 e Qz4, também de origem hidrotermal, são produtos de recristalização dos quartzos Qz1 e Qz2 durante os estágios finais da alteração hidrotermal. $\mathrm{Na}$ Tabela 3, estão sintetizadas as informaçôes texturais dos tipos de quartzo em correlação com as principais características das associaçóes minerais da área do depósito SJ.

\section{Alteração e evolução do quartzo}

Através de imagens de CL, cinco estágios de evolução do quartzo (Fig. 8), correlacionados às diferentes associaçóes minerais citadas anteriormente, foram propostos:

- Estágio 1 - corresponde à associação mineral 1 . A superfície do Qz1 luminescente (origem magmática), ainda preservada, fica em contato direto com fluidos hidrotermais magmáticos ou primários (alteração deutérica) e, portanto, mais suscetível à alteração do que o núcleo do cristal. O processo de dissoluçáo do cristal inicia pelas suas bordas expostas aos fluidos; nesse estágio, a rocha ainda preserva sua textura ígnea original.

- Estágio 2 - marca a transição entre as associaçôes minerais 1 e 2 , e corresponde à rocha magmática modificada. Os cristais de quartzo permanecem sob a ação contínua dos fluidos, o processo de dissolução aumenta e zonas de fraqueza são formadas nos cristais, facilitando o faturamento e a dissolução do Qz1. Esse estágio é correlacionável ao início da desestabilização dos minerais ferromagnesianos (anfibólio e biotita) que caracteriza a associação mineral 2.

- Estágio 3 - corresponde à associação mineral 3, caracterizada pela intensificaçáo dos processos hidrotermais. Os fluidos hidrotermais secundários passam a percolar as fraturas e a reagir com o Qz1, precipitando Qz2 de 
baixa luminescência (cinza). Esse estágio é correlacionável ao início da sulfetação e carbonatação da rocha.

- Estágio 4 - marca a transição entre as associações minerais 3 e 4 e corresponde ao aumento da mineralização em sulfetos (principalmente pirita) com Au associado. A precipitação de Qz2 nas fraturas e consequente dilatação do Qz1 aumentam, e novas fraturas seccionam Qz1 e Qz2, conferindo aspecto brechóide aos cristais.
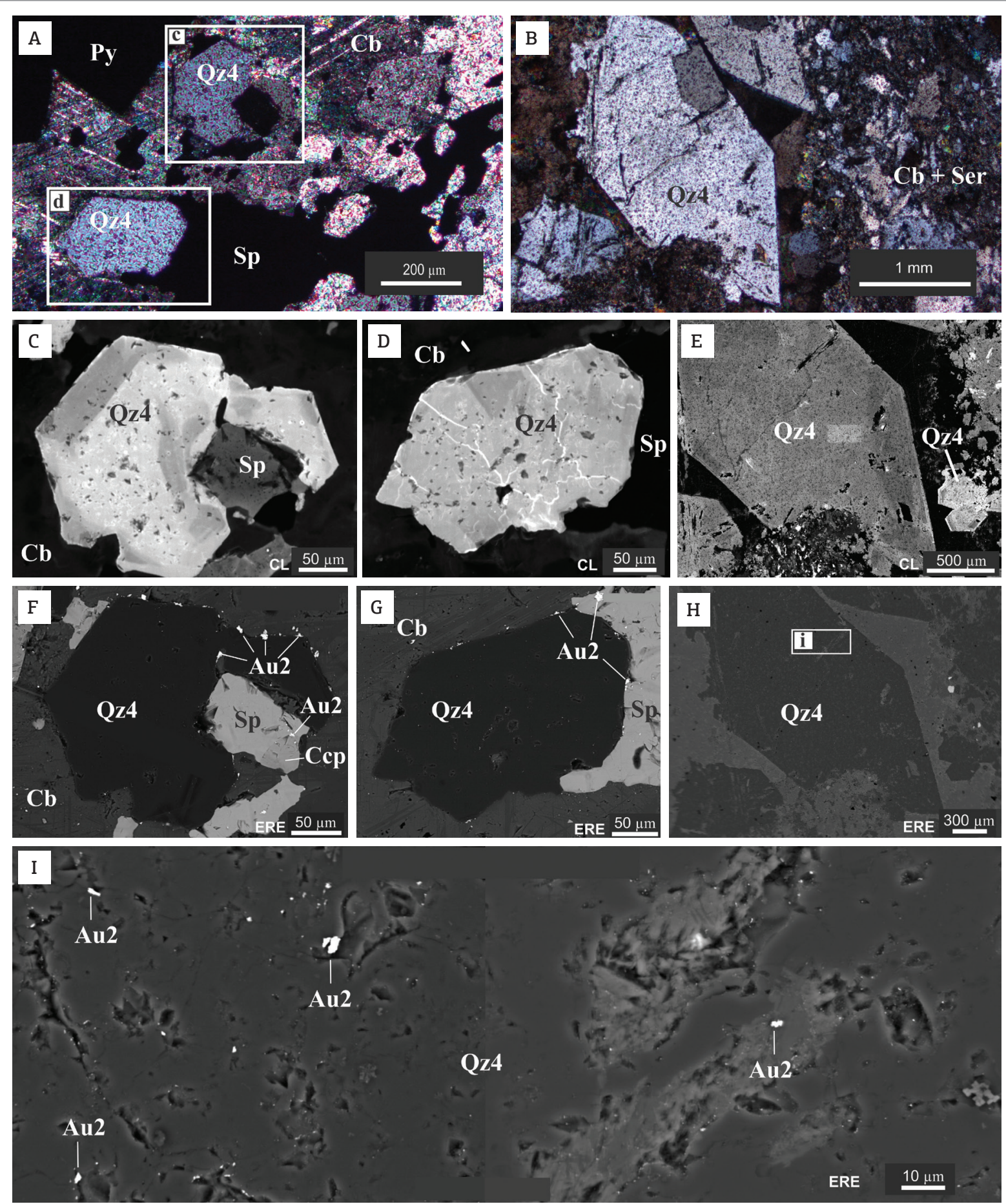

Py: pirita; Ccp: calcopirita; Sp: esfalerita; Au: ouro.

Figura 7. Segunda geração de ouro (Au2). (A) Fotomicrografia de Qz4 incluso em carbonato e em contato com esfalerita. (B) Fotomicrografia de Qz4 associado a carbonato e sericita. (C a E) Imagens de CL mostrando zoneamento no Qz4. ( $\mathrm{F}$ a H) Imagens de ERE utilizadas nas análises de EDS do Au2 presente nas bordas do Qz4 ou incluso neste e na esfalerita, sugerindo contemporaneidade entre essas fases minerais. (I) Detalhe da Figura $8 \mathrm{H}$ mostrando finos grãos de Au2 disseminados na estrutura do Qz4. 
Estágio 5 - corresponde exclusivamente à associação mineral 4, em que se estabeleceu o ápice da alteração hidrotermal; é caracterizado pela intensa ação dos fluidos hidrotermais mais tardios, acompanhada de alteração fílica, sulfetação e mineralização aurífera. Esse estágio é marcado pela geração de veios de quartzo $(\mathrm{Qz3})$ e cristais neoformados zonados $(\mathrm{Qz} 4)$ com inclusóes de partículas de ouro.

Tabela 2. Análises elementares médias por energy dispersive spectroscopy (\% peso) de fragmentos de ouro do depósito São Jorge.

\begin{tabular}{|c|c|c|c|c|c|c|c|c|c|}
\hline & Lâmina & As & Ag & Te & $\mathrm{Au}$ & $\mathbf{B i}$ & Total & $\mathrm{Au} / \mathrm{Ag}$ & $\mathrm{Au} / \mathrm{Te}$ \\
\hline \multirow{11}{*}{$\mathrm{Aul}$ (Py) } & FSJ-02-39 Img1 (1) & 0,45 & 8,79 & 0,38 & 88,57 & 1,79 & 100 & 10,07 & 233,07 \\
\hline & FSJ-02-39 Img3 (1) & 0,50 & 13,86 & 1,19 & 82,44 & 2,02 & 100 & 5,95 & 69,28 \\
\hline & FSJ-02-39 Img4 (3) & 0,42 & 14,57 & 0,77 & 82,41 & 1,83 & 100 & 5,66 & 107,03 \\
\hline & FSJ-02-45 Img3 (3) & 0,49 & 10,73 & 0,72 & 86,04 & 2,00 & 100 & 8,01 & 119,50 \\
\hline & FSJ-02-45 Img5 (1) & 0,35 & 1,11 & 0,58 & 96,35 & 1,60 & 100 & 87,59 & 166,12 \\
\hline & FSJ-02-45 Img6 (2) & 0,24 & 9,86 & 0,34 & 87,76 & 1,80 & 100 & 8,90 & 265,94 \\
\hline & FSJ-02-45 Img8 (2) & 0,17 & 7,82 & 0,52 & 89,86 & 1,64 & 100 & 11,49 & 176,20 \\
\hline & FSJ-04-07 Img2 (2) & 0,59 & 4,32 & 0,73 & 92,12 & 2,24 & 100 & 21,32 & 126,19 \\
\hline & FSJ-06-12 Img1 (3) & 0,28 & 8,98 & 0,46 & 88,47 & 1,81 & 100 & 9,86 & 192,33 \\
\hline & FSJ-06-16 Img3 (2) & 0,29 & 7,87 & 0,68 & 88,90 & 2,26 & 100 & 11,30 & 132,69 \\
\hline & FSJ-09-14 Img3 (2) & 0,29 & 23,74 & 0,22 & 73,91 & 1,84 & 100 & 3,11 & 335,91 \\
\hline \multirow{10}{*}{$\begin{array}{l}\mathrm{Au} 2 \\
(\mathrm{Sp}+\mathrm{Qz} 4)\end{array}$} & FSJ-02-22 Img1 (1) & 0,64 & 0,02 & 17,21 & 80,62 & 1,51 & 100 & 4031,00 & 4,68 \\
\hline & FSJ-02-22 Img2 (1) & 0,48 & 0,00 & 9,75 & 88,10 & 1,68 & 100 & - & 9,05 \\
\hline & FSJ-02-22 Img3 (1) & 0,67 & 0,83 & 2,77 & 93,54 & 2,19 & 100 & 112,70 & 33,89 \\
\hline & FSJ-02-25 Img1 (1) & 0,32 & 0,13 & 15,93 & 81,22 & 2,40 & 100 & 624,77 & 5,10 \\
\hline & FSJ-02-25 Img2 (2) & 0,51 & 0,02 & 5,39 & 92,27 & 1,82 & 100 & 5766,25 & 17,12 \\
\hline & FSJ-02-25 Img3 (4) & 0,53 & 0,07 & 14,54 & 82,99 & 1,88 & 100 & 1185,43 & 5,71 \\
\hline & FSJ-02-25 Img6 (3) & 0,48 & 0,05 & 1,32 & 95,87 & 2,28 & 100 & 1917,40 & 72,63 \\
\hline & FSJ-02-25 Img8 (3) & 0,59 & 0,00 & 1,14 & 95,63 & 2,65 & 100 & - & 84,63 \\
\hline & FSJ-02-25 Img9 (5) & 0,50 & 0,02 & 6,64 & 90,18 & 2,65 & 100 & 4509,00 & 13,58 \\
\hline & FSJ-02-25 Img11 (1) & 0,61 & 0,98 & 1,57 & 93,70 & 3,14 & 100 & 95,60 & 59,68 \\
\hline
\end{tabular}

Img: imagem ERE dos grãos de ouro analisados por EDS. Au1: primeira geração de ouro associada à pirita (Py); Au2: segunda geração de ouro associada ao Qz4 e esfalerita (Sp). Entre parênteses: número de análises pontuais realizadas. Au: ouro, Ag: prata, Te: telúrio, Bi: bismuto; As: Arsênio.

Tabela 3. Relação entre tipos de quartzo e associações minerais identificadas na área do depósito São Jorge.

\begin{tabular}{|c|c|c|c|c|}
\hline \multicolumn{2}{|c|}{ Tipos de quartzo em CL } & \multicolumn{3}{|c|}{ Dados comparativos (GSJJ, Borges et al. 2009) } \\
\hline $\begin{array}{l}\text { Quartzo } \\
\text { dominante }\end{array}$ & Características morfológicas & $\begin{array}{l}\text { Associação } \\
\text { mineral }\end{array}$ & $\begin{array}{l}\text { Temperatura } \\
\text { estimada/ Marcadores } \\
\text { mineralógicos }\end{array}$ & $\begin{array}{c}\text { Tipos } \\
\text { de alteração }\end{array}$ \\
\hline Qz1 & $\begin{array}{l}\text { Cristais anédricos médios, luminescentes, } \\
\text { com textura granular ígnea preservada. }\end{array}$ & $\begin{array}{l}\text { 1-Qz, Afs, } \mathrm{Pl}_{\text {(And-olig) }} \\
\text { Amp, Bt1, Ttn, Mgt, } \\
\text { Ilm, Zrn e Ap. }\end{array}$ & $\begin{array}{c}\geq 700^{\circ} \mathrm{C} \\
\text { Amp }+\mathrm{Pl}_{\text {(And-olig) }}\end{array}$ & Estágio magmático \\
\hline Qz2 (<Qz1) & $\begin{array}{c}\text { Cristais anédricos, luminescentes, } \\
\text { levemente fraturados (Qz1), seccionados } \\
\text { por vênulas de quartzo cinza pouco } \\
\text { luminescentes (Qz2). }\end{array}$ & $\begin{array}{l}\text { 2- Qz, Afs, } \mathrm{Pl}_{(\mathrm{Alb})}, \mathrm{Bt} 1, \\
\text { Ttn, Mag, Ilm, Zrn, Ap, } \\
\text { Ep e Chl. }\end{array}$ & $\begin{array}{l}450-350^{\circ} \mathrm{C} \\
\mathrm{Bt} 1+\mathrm{Ep}\end{array}$ & $\begin{array}{l}\text { Pós-magmática } \\
\text { (saussuritização) }\end{array}$ \\
\hline $\begin{array}{l}\text { Qz3 + Qz2 } \\
(>\mathrm{Qz1})\end{array}$ & $\begin{array}{l}\text { Cristais anédricos a subédricos, } \\
\text { luminescentes, intensamente fraturados } \\
\text { (Qz1), cortados por quartzo escuro } \\
\text { (Qz2), associados a cristais médios e } \\
\text { subédricos, moderadamente zonados } \\
\text { (Qz3), que constituem os veios de quartzo } \\
\text { (Qz3+Qz2 } \pm \text { Qz1). }\end{array}$ & $\begin{array}{l}\text { 3- Qz, Pl } \\
\text { Chl, Cb, Ser, }, \text { Py, Zrn } \\
\text { e Ap. }\end{array}$ & $\begin{array}{c}340-280^{\circ} \mathrm{C} \\
\text { Chl + illita }+\mathrm{Pl} \\
\text { descalcificado+Bt2 }\end{array}$ & $\begin{array}{l}\text { Propilítica } \\
\text { (cloritização) }\end{array}$ \\
\hline $\begin{array}{l}\mathrm{Qz4}+\mathrm{Qz3} \\
(>\mathrm{Qz2})\end{array}$ & $\begin{array}{l}\text { Cristais neoformados, euédricos, finos a } \\
\text { médios, com zoneamento oscilatório bem } \\
\text { definido (Qz4), hospedeiros do Au. }\end{array}$ & $\begin{array}{l}\text { 4- Qz, Bt3, Cb, Ser, } \\
\text { Chl, Py, Ccp, Sp e Au. }\end{array}$ & $\begin{array}{c}\leq 300^{\circ} \mathrm{C} \\
\text { Mica } \\
\text { branca }+\mathrm{Cb}+\mathrm{Chl}+\mathrm{Py}+\mathrm{Bt} 3\end{array}$ & $\begin{array}{l}\text { Fílica (carbonatação, } \\
\text { sericitização, } \\
\text { sulfetação) }\end{array}$ \\
\hline
\end{tabular}

Qz1, Qz2, Qz3, Qz4: conforme Fig. 5. Qz: quartzo, Afs: feldspato potássico, Ab: albita, Pl: plagioclásio, Amp: anfibólio, Ttn: titanita, Mag: magnetita, Olig: oligoclásio, Ilm: ilmenita, Zrn: zircão, Ap: apatita, Ep: epidoto, Chl: clorita, Cb: carbonato, Ser: sericita, Py: pirita, Ccp: calcopirita, Sp: esfalerita e Au: ouro. Bt1: biotita marrom. Bt2: biotita marrom esverdeada. Bt3: biotita verde clara de granulação muito fina. And: andesina. Abreviações segundo Whitney \& Evans (2010). 


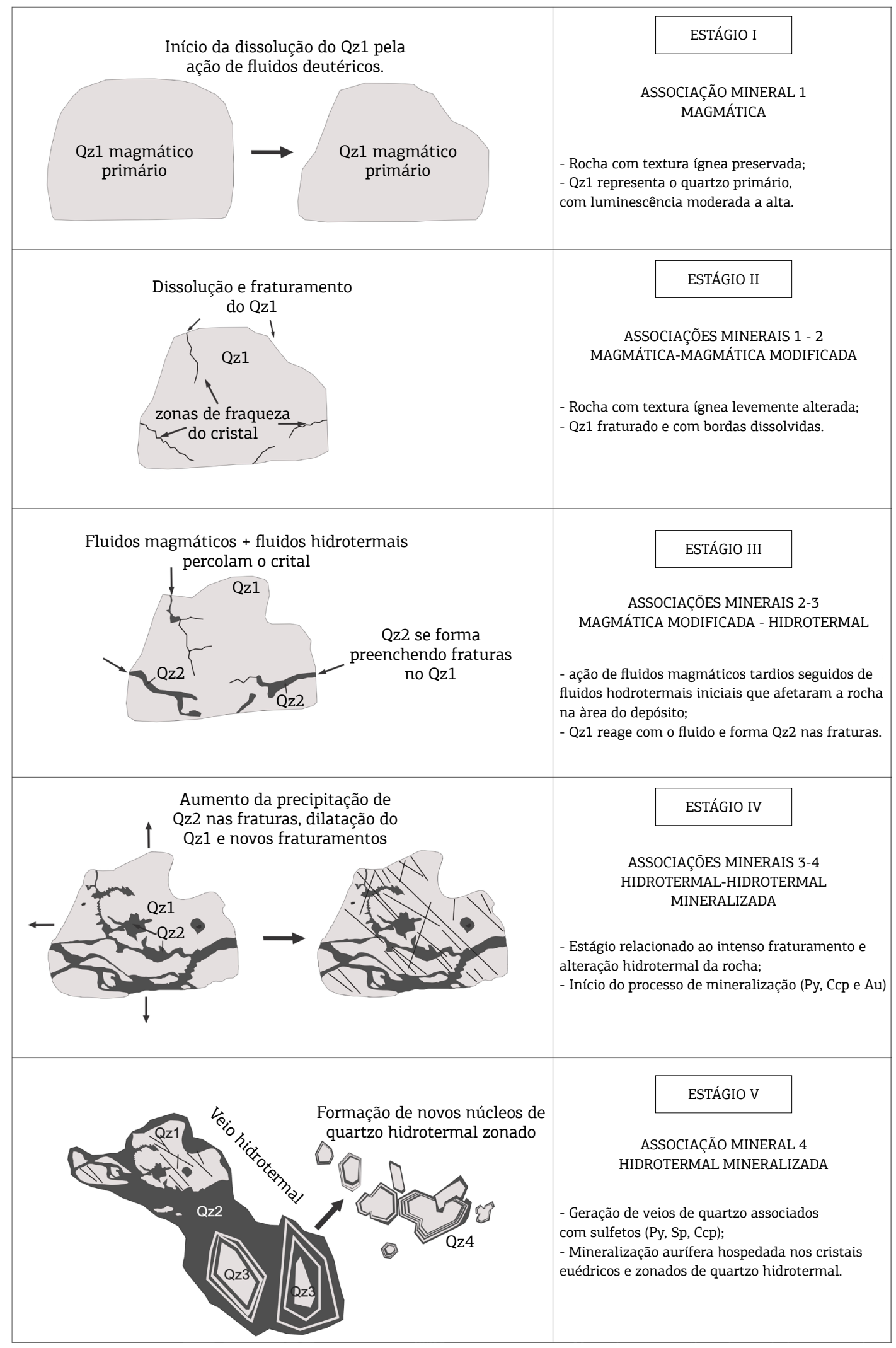

Qz: quartzo, Py: pirita, Sp: esfalerita, Brt: barita, Cb: carbonato. Abreviações segundo Whitney \& Evans (2010).

Figura 8. Esquema de alteração e evolução do quartzo em catodoluminescência. Estágio I - (Qz1) representa o quartzo luminescente de origem magmática. Estágio II - Qz1 fraturado e com bordas corroídas. Estágio III - Qz1 reage com os fluidos hidrotermais, cristalizando Qz2 escuro nas fraturas. Estágio IV - aumento na formação de Qz2 concomitante com o processo de mineralização da rocha. Estágio V - Geração de veios e novos núcleos de quartzo hidrotermal zonado (Qz3 e Qz4). 


\section{Implicações metalogenéticas}

A mineralização presente no depósito São Jorge é representada por sulfetos (principalmente pirita, esfalerita e calcopirita) e ouro, presente nos veios ou disseminados na rocha alterada (associaçóes 3 e 4). A pirita é o sulfeto mais abundante; ocorre principalmente nos veios de quartzo, forma cristais euédricos a subédricos, finos a médios $(200-900 \mu \mathrm{m})$, associados ao carbonato; formou-se na rocha a partir da associação 3 (ver Tab. 3). A esfalerita é o segundo sulfeto mais abundante; forma cristais anédricos subédricos, inclusos no carbonato ou em contato com o Qz4; está presente nas zonas intensamente sericitizadas. A calcopirita ocorre em menor quantidade, geralmente inclusa na pirita ou disseminada nos veios. O ouro ocorre incluso nos cristais de pirita e esfalerita ou preenchendo fraturas neles; ocorre também associado aos cristais de quartzo (Qz4) e carbonato.

A origem dos sulfetos ou a fonte dos metais ( $\mathrm{Fe}, \mathrm{Cu}$ e Zn) pode estar diretamente relacionada à composição química da rocha hospedeira e aos fluidos hidrotermais atuantes. Os fluidos quentes circulam com facilidade pelas fraturas e resfriam de maneira rápida ao entrar em contato com a rocha fria, beneficiando a precipitação dos metais. Em seu estudo metalogenético do GSJJ, Borges (2010) sugeriu que o fluido hidrotermal rico em metais deu origem aos veios de quartzo mineralizados, e que o ouro foi transportado como tiocomplexo, principalmente $\mathrm{Au}(\mathrm{HS})_{2}$ e $\mathrm{HAu}(\mathrm{HS})_{2}$. Através da composição química desses tiocomplexos, pode-se inferir que os fluidos hidrotermais transportavam conteúdos de íon $\mathrm{S}$. Quanto aos íons $\mathrm{Fe}^{+2}, \mathrm{Cu}^{+2} \mathrm{e} \mathrm{Zn}^{+}$, podem ter sido liberados das rochas do GSJJ quando atingidas pelos fluidos, permitindo a reação $\mathrm{S}^{-}+\mathrm{Fe}^{+2} \pm \mathrm{Cu}^{+2}$, formando as fases sulfetadas pirita, e mais raramente calcopirita. Consequentemente, com

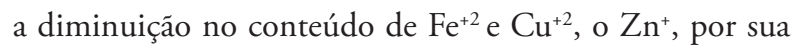
vez, começou a reagir com o $S$, gerando sulfetos mais tardios na associação 4 (principalmente esfalerita, ver Tab. 3). A constante diminuição da concentração de $S^{-}$no fluido e a contínua presença de íons metálicos podem ter provocado a quebra dos tiocomplexos $\mathrm{Au}(\mathrm{HS})_{2}$ e $\mathrm{HAu}(\mathrm{HS})_{2}$, liberando novos íons $\mathrm{S}^{-}$(para reagir com o $\mathrm{Zn}^{+}$restante no sistema) e precipitando partículas de ouro sobre os minerais pré-existentes (pirita, esfalerita, carbonatos e quartzo hidrotermal).

As análises por EDS indicam dois tipos de ouro quimicamente distintos: Au1 enriquecido em $\mathrm{Ag}$ e associado à pirita, e Au2 enriquecido em Te e associado à esfalerita e ao Qz4, ambos formados nos estágios mais avançados do hidrotermalismo. A diferença composicional Au 1 e Au2 pode ser melhor observada nos diagramas geoquímicos envolvendo $\mathrm{Au}, \mathrm{Ag}$ e Te. No diagrama Au versus Ag (Fig. 9A), o Aul associado a cristais de pirita mostra um trend de enriquecimento em Ag e um decréscimo no conteúdo de Au, o que pode indicar a substituição de $\mathrm{Au}$ por $\mathrm{Ag}$, enquanto o Au2 associado ao Qz4, esfalerita e calcopirita, apresenta comportamento inverso. Por outro lado, o diagrama $\mathrm{Au}$ versus $\mathrm{Te}$ (Fig. 9B) mostra que o Au2 se enriquece em Te enquanto o Au1 empobrece. No diagrama envolvendo as razóes $\mathrm{Au} /$ $\mathrm{Ag}$ versus $\mathrm{Au} / \mathrm{Te}$ (Fig. 9C), Au1 e Au2 apresentam trends inversos. O diagrama ternário que relaciona $\mathrm{Au}, \mathrm{Ag} / 2$ e Te/2 (Fig. 9D) também apresenta uma forte separação composicional entre as duas geraçóes de ouro.

O estudo não permitiu a identificação das possíveis fontes desses metais presentes na composição química do ouro. Sabe-se que a presença de teluretos e selenetos de prata são comuns na composição química de minérios de outros depósitos da região. No depósito aurífero da Mina do Palito, localizado nesta mesma província aurífera, teluretos e selenetos de bismuto e prata, sulfossais e ligas de ouro e prata (com 25 a 30\% de Ag) são típicos do minério (Juliani et al. 2002). As possíveis causas das variaçóes químicas do ouro podem ser explicadas por processos de substituição iônica entre Au, Ag e Te, mobilidade química (Ag e Te), mecanismo de precipitação (reação fluido-rocha, mistura de fluidos, separação de fases), variaçóes no $\mathrm{pH}, \mathrm{fO}_{2}$, T. Entretanto, uma abordagem mais precisa de tais processos está além dos reais objetivos deste estudo.

\section{CONCLUSÕES}

Os aspectos petrográficos e mineralógicos das rochas do GSJJ, bem como os diferentes níveis de alteração hidrotermal e a mineralização presente na área do depósito SJ, são parâmetros que podem auxiliar os estudos de quartzo por meio de MEV-CL. Este estudo permitiu estabelecer uma relação direta e cronológica entre a evolução morfológico-textural do quartzo e os processos de alteração e mineralização da rocha. Quatro geraçôes de quartzo foram identificadas por CL: a primeira de origem magmática (Qz1 luminescente) presente nas rochas estéreis; a segunda $(\mathrm{Qz} 2$, não luminescente), provavelmente de temperatura mais baixa e associada aos estágios tardimagmáticos, marca o início da alteração textural do quartzo e possivelmente o início da alteração hidrotermal da rocha hospedeira; a terceira e a quarta geraçôes de origem tipicamente hidrotermal (Qz3 e Qz4 zonados), presentes nas rochas intensamente hidrotermalizadas e mineralizadas. O Qz4 representa a geração mais tardia, ocorrendo na forma de cristais neoformados, zonados, inclusos no carbonato e na sericita ou em contato com eles; representa um marcador da mineralização aurífera do GSJJ. Imagens de ERE-CL e análises de EDS indicam que a mineralização aurífera do depósito SJ está presente nas porçóes mais hidrotermalizadas e é representada por 


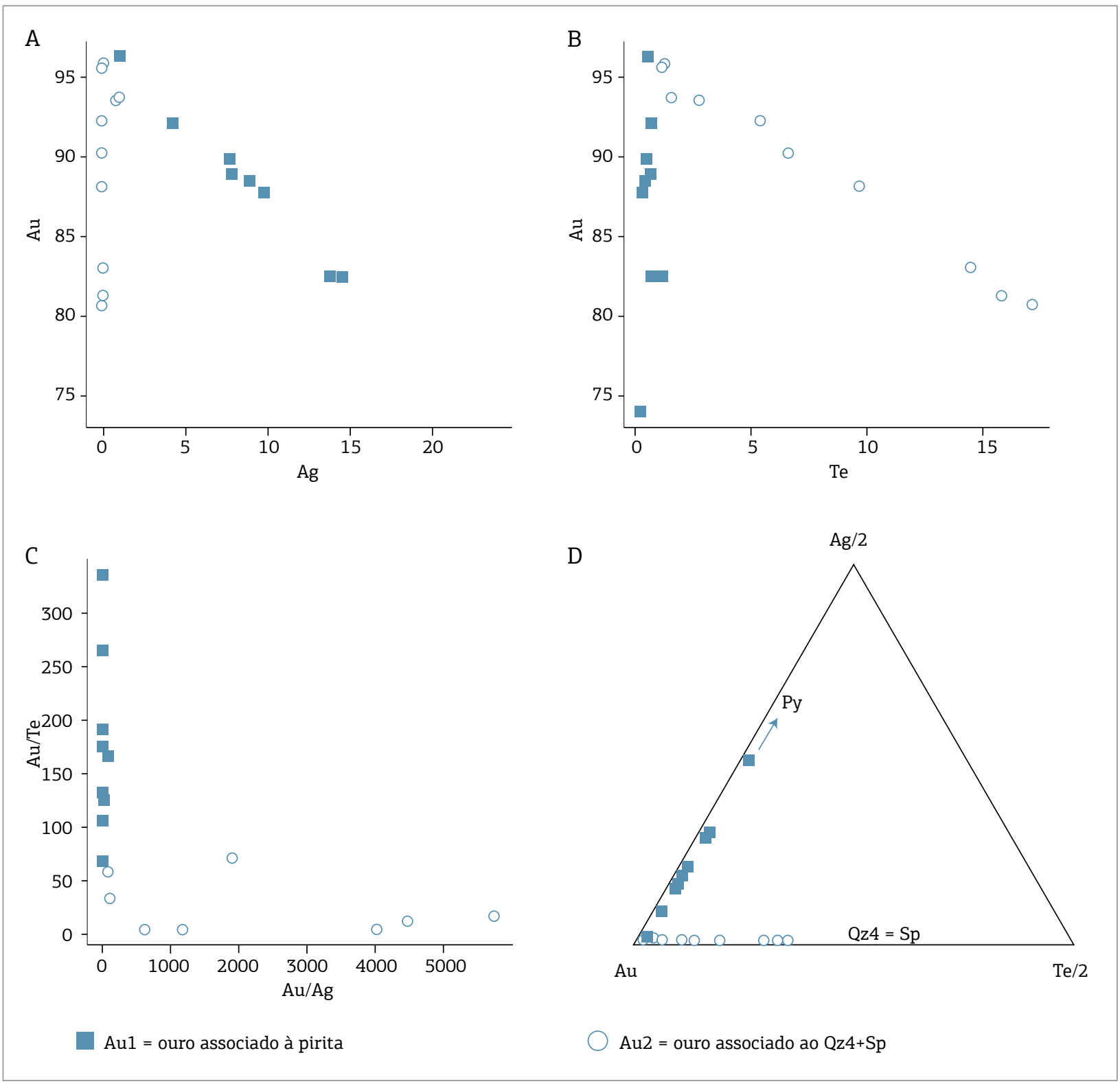

Figura 9. Diagramas composicionais mostrando as relações entre conteúdos de $\mathrm{Au}, \mathrm{Ag}$ e $\mathrm{Te}$ (\% em peso) das gerações Au1 e Au2. (A) Au versus Ag. (B) Au versus Te. (C) $\mathrm{Au} / \mathrm{Te}$ versus $\mathrm{Au} / \mathrm{Ag}$. (D) $\mathrm{Au}-\mathrm{Ag} / 2-\mathrm{Te} / 2$. Análises obtidas por energy dispersive spectroscopy.

duas geraçôes quimicamente distintas: a primeira (Au1), enriquecida em Ag e inclusa ou preenchendo fraturas na pirita; a segunda (Au2), com teores elevados de Te e associada ou hospedada em cristais de Qz4, esfalerita e, mais raramente, calcopirita. Este estudo mostrou que cristais de quartzo podem representar um excelente marcador da evolução magmática, das alteraçóes hidrotermais e da mineralização aurífera correspondentes às rochas do depósito $\mathrm{SJ}$. A metodologia MEV-CL em cristais de quartzo se firma como importante ferramenta complementar em estudos petrológicos e metalogenéticos.

\section{AGRADECIMENTOS}

Ao Instituto de Geociências da Universidade Federal do Pará (UFPA), ao Programa de Pós-graduação em Geologia e Geoquímica (PPGG) e ao Grupo de Pesquisa Petrologia de Granitoides (GPPG) da UFPA, ao geólogo Dr. Marcelo Lacerda Vasquez da CPRM-Belém. Este trabalho é uma contribuição ao Instituto de Geociências da Amazônia (GEOCIAM) (programa INCT - CNPq/MCT/FAPESPA - processo 573733/2008-2), com apoio financeiro da Coordenação de Aperfeiçoamento de Pessoal de Nível Superior - CAPES. 


\section{REFERÊNCIAS}

Borges R.M.K., Dall'Agnol R., Lamarão C.N., Figueiredo M.A.B., Leite A.A. Da Silva, Barros C.E.M., Costi H.T. 2009. Petrografia, química mineral e processos hidrotermais associados ao depósito de ouro São Jorge, Província Aurífera do Tapajós, Cráton Amazônico. Revista Brasileira de Geociências, 39(2):375-393.

Borges A.W.G. 2010. Geologia e metalogênese do depósito aurífero São Jorge, Província Aurífera do Tapajós, Novo Progresso-PA. MS Dissertation, Instituto de Geociências, Universidade Federal do Pará, Belém, 58 p.

Breiter K., Müller A. 2009. Evolution of rare-metal granitic magmas documented by quartz chemistry. European Journal of Mineralogy, 21:335-346

D'Lemos R.S., Kearsley A.T., Pembroke J.W., Watt G.R., Wright P. 1997. Complex quartz growth histories in granite revealed by scanning cathodoluminescence techniques. Geological Magazine, 134:549-552.

Faraco M.T.L., Carvalho J.M.A., Klein E.L. 1997. Carta metalogenética da Província Aurífera do Tapajós. In: Costa M.L. \& Angélica R.S. (Coord.). Contribuições à geologia da Amazônia. Belém: FINEP/SBGNúcleo Norte, p. 423-443.

Ferreira A.L., Almeida M.E., Brito M.F.L., Monteiro M.A.S. 2000. Geologia e recursos minerais da Folha Jacareacanga (SB.21Y-B), Estados do Amazonas e Pará. Nota explicativa, Projeto Especial Província Mineral do Tapajós. Manaus, PROMIM Tapajós/CPRM, escala 1: 250.000. 1 CD-ROM.

Hogan J.P. 1993. Monomineralic glomerocrysts: Textural evidence for mineral resorption during crystallization of igneous rocks. Journal of Geology, 101:531-540.

Juliani C., Corrêa-Silva R.H., Monteiro L.V.S., Bettencourt J.S., Nunes C.M.D. 2002. The Batalha Au-granite system Tapajós Gold Province, Amazonian Craton, Brazil: hydrothermal alteration and regional implications. Precambrian Research, 199(1-4):225-256.

Klein E.L., Vasquez M.L. 2000. Geologia e recursos minerais da Folha Vila Riozinho SB.21-Z-A, Estado do Pará, escala 1:250.000. Brasília: CPRM, 1 CD-ROM. Programa Levantamentos Geológicos Básicos do Brasil (PLGB). Projeto Especial Província Mineral do Tapajós (Promin Tapajós).

Klein E.L., Santos R.A., Fuzikawa K., Angélica R.S. 2001. Hydrotermal fluid evolution and structural control of the Guarim mineralization, Tapajós Province, Amazonian craton, Brazil. Mineralium Deposita, 36(2):149-164.

Lamarão C.N. \& Dall'Agnol R. 2002. Granitóides São Jorge Antigo e São Jorge Jovem: petrografia e geoquímica de magmatismo cálcicoalcalino alto-K paleoproterozóico na Província Aurífera do Tapajós, Cráton Amazônico. In: Klein E.L., Vasquez M.L., Rosa-Costa L.T. (Eds.). Contribuições à Geologia da Amazônia, SBG-NO, Belém, 3:53-66.

Lamarão C.N., Dall'Agnol R., Lafon J.M., Lima E.F. 2002. Geology, geochemistry and $\mathrm{Pb}-\mathrm{Pb}$ zircon geochronology of the paleoproterozoic magmatism of Vila Riozinho, Tapajós Gold Province Amazonian Craton, Brazil. Precambrian Research, 119:189-223.

Lamarão C.N., Dall'Agnol R., Pimentel M.M. 2005. Nd isotopic composition of Paleoproterozoic volcanic and granitoid rocks of Vila Riozinho: implications of the crustal evolution of the Tapajós gold province, Amazon craton. Journal of South American Earth Sciences, 18:277-292.

Lamarão C.N., Souza K.S., Dall' Agnol R., Galarza M.A. 2008. Granitos pórfiros da região de vila Riozinho, província aurífera do Tapajós: petrografia e geocronologia. Revista Brasileira de Geociências, 38(3):533-543.

Lamarão C.N., Rocha K.K.N., Marques G.T., Borges R.M.K. 2013. Quartzo e zircão como marcadores da evolução magmáticohidrotermal do Granito Antônio Vicente, Suíte Intrusiva Velho Guilherme, Província Carajás. Revista do Instituto de Geociências USP, São Paulo, 13(2):4-68.

Lamarão C.N., Silva J.S., Borges R.M.K., Dall'Agnol R. 2014. Morphological and compositional variations of zircon and their metallogenetic implications: the example of the Jamon, Serra dos Carajás and Velho Guilherme suites, Amazonian Craton. Brazilian Journal of Geology, 44(1):105-120.

Landtwing M.R. \& Pettke T. 2005. Relationships between SEMcathodoluminescence response and trace-element composition of hydrothermal vein quartz. American Mineralogist, 90:122-131.

Larsen R.B., Jacamon F., Kronz A. 2009. Trace element chemistry and textures of quartz during the magmatic hydrothermal transition of Oslo Rift granites. Mineralogical Magazine, 37(4):691-707.

Loomis T.P. \& Welber P.W. 1982. Crystallization processes in the Rocky Hill granodiorite Pluton, California: An interpretation based on compositional zoning of plagioclase. Contribution to Mineralogy and Petrology, 8(14):230-239.

Melo A.F.F., Andrade A.F., Yamaguti H.S., Oliveira J.R., Carmona J.R.M., D’antona R.J.G., Lopes R.C. 1980. Projeto Tapajós-Sucunduri. CPRM/ DNPM, v. 1A, p.1-356.

Müller A., Seltaman R., Behr H-J. 2000. Application of cathodoluminescence to magmatic quartz in a tin granite-case study from the Schellerhau granite Complex, Eastern Erzgebirge, Germany. Mineralium Deposita, 35:169-218.

Müller A., Kronz A., Breiter K. 2002. Trace elementsand growth pattern in quartz: a fingerprint of the evolution of the subvolcanic Podlesí Granite System (Krusné Hory, Czech Republic). Bulletin of Czech Geological Survey, 77:135-145.

Müller A., René M., Behr H. J., Kronz A. 2003. Trace elements and cathodoluminescence in igneous quartz in topaz granites from the Hub Stock (Slavkovský Les Mts., Czech republic). Mineralogy and Petrology, 79:167-191.

Müller A., Breiter K., Seltmann R, Pécskay Z. 2005. Quartz and feldspar zoning in the eastern Erzgebirge volcano-plutonic complex (Germany, Czech Republic): evidence of multiple magma mixing. Lithos, 80:201-227.

Pessoa M.R., Santiago A.F., Andrade A.F., Barreto E.L., Nascimento J.O., Santos J.O.S., Oliveira J.R., Lopes R.C., Prazeres W.V. 1977. Projeto Jamanxim. CPRM/DNPM, 1-3:614 p.

Quadros M.L.E.S., Bahia R.B.C., Klein E.L., Vasquez M.L., Almeida M.E., Ricci P.S.F. 1999. As intrusões básicas da Província Mineral do Tapajós (PMT) e possibilidades de mineralizações associadas. In: 60 Simpósio de Geologia da Amazônia, Manaus, Brasil, Anais, p. 567-569.

Ricci P.S.F., Vasquez M.L., Santos A., Klein E.L., Jorge João X.S., Martins R.C. 1999. Suíte Intrusiva Creporizão - Província Tapajós: proposta e critérios de definição. In: $6^{\circ}$ Simpósio de Geologia da Amazônia, Manaus, Brasil, Anais, p. 519-522.

Rusk B.G. \& Reed M.H. 2002. Scanning electron microscope cathodoluminescence analysis of quartz reveals complex growth histories in veins from the Butte porphyry copper deposit, Montana. Geology, 30(8):727-730. 
Rusk B.G., Reed M.H., Dilles J.H., Kenti A.J.R. 2006. Intensity of quartz cathodoluminescence and trace-element content in quartz from the porphyry copper deposit at Butte, Montana. American Mineralogist, 91:1300-1312.

Rusk B.G., Lowers H.A., Reed M.H. 2008. Trace elements in hydrothermal quartz: Relationships to cathodoluminescent textures and insights into vein formation. The Geological Society of America, 36(7):547-550.

Santos J.O.S., Hartmann L.A., Gaudette H.E., Groves D.I., Mcnaughton N.J., Fletcher I.R. 2000. A new understanding of the Provinces of the Amazon Craton based on integration of field and U-Pb and Sm-Nd geochronology. Gondwana Research, 3:453-488.

Santos J.O.S., Hartmann L.A., McNaughton N.J., Fletcher I.R. 2001. Timing of mafic magmatism in the Tapajós Province (Brazil) and implications for the evolution of the Amazon Craton: evidence from baddeleyite and zircon U-Pb SHRIMP geochronology. Journal South American Earth Science, 15:409-429.

Sato K. \& Tassinari C.C.G. 1997. Principais eventos de acresção continental no Cráton Amazônico baseados em idade-modelo Sm-Nd, calculada em evoluções de estágio único e estágio duplo. In: Costa M.L.C. \& Angélica R.S. (eds.). Contribuições à Geologia da Amazônia, Belém. Simpósio Brasileiro de Geologia, 1:91-142.

Slaby E., Götze J., Wörner G., Wrzalik R., Smigieski M. 2008. K-feldspar phenocrysts in microgranular magmatic enclaves: a cathodoluminescence and geochemical study of crystal growth as a marker of magma mingling dynamics. Lithos, 105:85-97.

Tassinari C.C.G. \& Macambira M.J.B. 1999. Geochronological Provinces of the Amazonian Craton. Episodes, 22:174-182.

Tassinari C.C.G. \& Macambira M.J.B. 2004. A evolução tectônica do Cráton Amazônico. In: Mantesso-Neto V., Bartorelli A., Carneiro C.D.R.,
Brito Neves B.B. Geologia do Continente Sul-Americano: Evolução da Obra de Fernando Flávio Marques de Almeida. p. 471-485.

Vasquez M.L. \& Klein E.L. 2000. Geologia e recursos minerais da Folha Rio Novo - SB.21 - Z- C, Estado do Pará. Nota explicativa. Projeto Especial Província Mineral do Tapajós. Brasília, CPRM, PROMIM Tapajós, escala 1:250.000. 1 CD-Rom.

Vasquez M.L., Klein E.L., Ricci P. 2002. Granitoides pós-colisionais da porção leste da Província Tapajós. In: Klein E.L., Vasquez M.L., Rosa-Costa L.T. (Ed.). Contribuições à Geologia da Amazônia, Belém. Simpósio Brasileiro de Geologia, 3:67-84.

Vasquez L.V., Rosa-Costa LR., Silva C.G., Ricci P.F., Barbosa J.O., Klein E.L, Lopes E.S., Macambira E.B., Chaves C.L., Carvalho J.M., Oliveira J.G., Anjos G.C., Silva H.R. 2008. Geologia e Recursos Minerais do Estado do Pará: Sistema de Informações Geográficas - SIG: texto explicativo dos mapas Geológico e Tectônico e de Recursos Minerais do Estado do Pará. Organizadores, Vasquez M.L, Rosa-Costa L.T. Escala 1:1.000.000. Belém: CPRM.

Vasyukova O.V., Kamenetsky V.S., Goemann K., Davidson P. 2013. Diversity of primary CL textures in quartz from porphyry environments: implication for origin of quartz eyes. Contribution to Mineralogy and Petrology, 166:1253-1268.

Wark D.A. \& Watson E.B. 2006. The TitaniQ: a Titanium-in-Quartz Geothermometer. Contribuitions to Mineral Petrology, (152):743-754.

Whitney D.L. \& Evans B.W. 2010. Abbreviations for names of rockforming minerals. American Mineralogist, 95:185-187.

Wiebe R.A., Wark D.A., Hawkins D.P. 2007. Insights from quartz cathodoluminescence zoning into crystallization of the Vinalhaven granite, coastal Maine. Contribution to Mineralogy and Petrology, 154:439-453.

$\overline{\text { Arquivo digital disponível on-line no site www.sbgeo.org.br }}$ 